\title{
Son Yıllarda Meydana Gelen Hastane Yangınları ve Nedenleri Üzerine Bir Araştırma
}

\author{
Zehra Yıldız ${ }^{1 *} \mathbb{\infty}$, Gülendam Çelik² \\ ${ }^{1}$ Tarsus Üniversitesi, Teknoloji Fakültesi, Enerji Sistemleri Mühendisliği Bölümü, Mersin. \\ ${ }^{2}$ Tarsus Üniversitesi, Lisansüstü Eğitim Enstitüsü, İş Sağı̆ğı ve Güvenliği Anabilim Dalı, Mersin.
}

\section{Özet}

Ülkemizde sağlık hizmetleri, sağlık bakanlı̆̆ına ve üniversitelere bağlı kamu hastaneleri ile özel hastaneler tarafindan sağlanmaktadır. Üniversite araştırma hastaneleri, sağlık bakanlığından sonra en önemli sağlık hizmeti veren kurumlardır. Üniversitedeki sağllk hizmetleri, sağllk sistemi içerisinde doğrudan hasta tedavisi ve bakımının yanı sira çeşitli săğlk eğitimi ve tıbbı araştırma faaliyetlerini de kapsamaktadır. Bu yüzden üniversite sağllk kurumları diğer hastanelere göre daha kompleks ve kalabalıktır. Bu sağllk kurumlarında poliklinikler, derslikler, laboratuvarlar, yemekhane, ofisler, mutfak, kazan dairesi, çatı katı, arşiv, elektrik tesisatı, parlayıcı ve patlayıcı maddeler, oksijen sistemleri gibi birçok mekân tek çatı altında toplanmaktadır. Bununla birlikte üniversite hastanelerinde diğer hastanelere göre çalışan, ögrenci, hasta ve ziyaretçi sayısı daha fazladır. Bu nedenle özellikle üniversite hastanelerinde meydana gelebilecek bir yangin felakete sebep olabilir. Yangın tehlikesi açısından orta tehlikeli sınıfta yer alan hastanelerde yangın güvenlik önlemlerinin en üst safhada olması gerekmektedir. Bu çalışmada, ülkemizde faaliyet gösteren hastanelerde son yıllarda çıkan yangınlar, yangın nedenleri ve alınması gereken yangın önlemleri açısından değerlendirilmiştir. Ülkemizde hastanelerde son yıllarda meydana gelen yangınların başlıca elektrik ve dikkatsizlik nedeniyle çıktı̆̆ belirlenmiştir. Să̆lık kurumlarında, bina tasarımında önemli rol oynayan pasif sistemler ve yangın olayının büyümesine müsaade etmeyen aktif söndürme sistemlerinin günümüz teknolojisine uygun dizayn edilmesi ile yangın riski ortadan kaldırılabilir ya da risk minimuma indirilebilir.

\section{$\underline{\text { Anahtar Sözcükler }}$}

Yangın, Hastane, Hastane Yangınları

\section{A Research on Recent Hospital Fires and Their Causes}

\begin{abstract}
In our country, health services are provided by public hospitals affiliated to the health ministry and universities along with private hospitals. University research hospitals are the most important healthcare institutions after the ministry of health. In addition to direct patient treatment and care in the healthcare system, the health services at universities involve various health education and medical research activities as well. Therefore, university health institutions are more complex and crowded than other hospitals. In these health institutions, many spaces such as policlinics, classrooms, laboratories, cafeteria, offices, kitchen, boiler room, penthouse, archive, electrical installation, flammable and explosive materials, oxygen systems are gathered under a single roof. Moreover, the number of employees, students, patients and visitors is higher in university hospitals compared to other hospitals. For this reason, a fire especially in university hospitals may lead to a disaster. Fire safety measures should be at the highest level in hospitals that are located in the middle dangerous class in terms of fire hazard. In this study, recent fires occurred in the currently operating hospitals in the country are evaluated in terms of fire causes and fire precautions to be taken. It was determined that the recent fires occurring in university hospitals in our country are mainly started due to electricity and carelessness. With planning -according to today's technology- both passive systems that play an important role in the design of buildings and active extinguishing systems that do not allow fire incidents to grow, the risk of fire in health institutions can be eliminated or minimized.
\end{abstract}

\section{$\underline{\text { Keywords }}$}

Fire, Hospital, Hospital Fires

\section{Giriş}

Binalarda yangın tehlikesi, yangın yükü indeksine göre belirlenir. Yangın yükü indeksi, bir yapı içerisinde birim alanı başına bulunan potansiyel yanıcı madde miktarıdır. Yangın yükü indeksi, yapıların sıklı̆̆ı, yapı şekli, boyutu, yapı malzemesi ve kullanımı gibi faktörlere bağlıdır. Binalar yangın yükü indeksine göre düşük, orta, yüksek ve çok yüksek diye ayrılır. Hastane binaları, yangın yükü indeksine göre orta sınıfta yer alan binalardır. Hastane binalarını, birimlerin, çalışanlarının ve hasta sayısının fazla olması nedeniyle yangından korumak zordur. 
Hastaneler büyük ve karışık yapıları gereği yangın dışında birçok tehlike ve riski bünyesinde tek başına barındırmaktadır. Ayrıca hastaneler İş Sağlığı ve Güvenliğine ilişkin İşyeri Tehlike Sınıfları Tebliğine göre ‘Çok Tehlikeli İşyeri’ sınıfında yer almaktadir.

Ülkemizde şehir hastaneleri ile entegre sağlık tesisi projeleri geliştirilmekte ve özel hastanelerin sayısı giderek artmaktadır. Hastanelerde çalışan yoğunluğu ve kullanıcı profilinin fazla olması, tedavi gören hastaların hareket yeteneklerinin az veya hiç olmaması, laboratuvar, eczane ve tıbbi atık depo, ameliyathaneler, hasta bakım odaları, yoğun bakım birimleri, yüksek basınç odaları, depo, arşiv ve elektrik dağıtım odaları gibi birçok tehlikeli mekânı tek çatı altında topladığı için hastaneler açısından yangın güvenliği çok büyük önem arz etmektedir. Hastanelerde uygulanması gereken yangın güvenlik önlemleri ve tahliye ihtiyacı mevcut mevzuata ve standartlara tamamen uygun olmalıdır. Bu kapsamda hastaneler yangınla mücadeleye hazır olmalıdır. Yangının hastanelerde meydana gelmemesi için tüm tedbirler alınmalıdır. Yangın güvenlik önlemleri aktif ve pasif yangın güvenlik önlemleri olmak üzere ikiye ayrılır. Pasif yangın güvelik önlemleri, binanın kuruluş projelendirme ve tasarım aşamasında yer alır. Bu önlemler yapı kullanma şekline bağlı olarak, yapının mimari tasarımı, bina strüktürünün tayin edilmesi, yapı malzemesinin seçimi, pasif yangın güvenliği önlemlerinin temelini oluşturmaktadır. Yapıda kullanılan bileşen ile malzemelerin yangına dirençli olması, yangının büyüyüp gelişmesini önleyici türde olması gerekir. Proje tasarlanırken, yangın önleyici tedbirler ile yangın söndürme kolaylığı da göz önüne alınmalıdır. Pasif yangın önleme yöntemleri aynı zamanda yangın söndürmeye de destek verecek şekilde olmalıdır (Kılıç ve Beceren 1999). Aktif yangın güvenlik önlemleri ise doğrudan yangın oluşumu ile ilgili önlemlerdir. Aktif yangın güvenlik önlemleri, yapının inşası sırasında veya daha sonra uygulanan ve sadece yangın çıktığı zaman işlev gören, bir enerjinin kullanımı sonucunda etkin olabilen, belirli bir hedefe yönelmiş önlemlerdir. Bu önlemler; algılama sistemleri, yangın kontrol sistemleri, yangın güvenliği yönetim sistemleri, uyarı sistemleri, duman kontrol sistemleri, basınçlanma ve havalandırma sistemleri, söndürme sistemleridir (Başdemir ve Demirel 2010; Kilıç 2003). Bu iki yangın güvenlik sistemi koordineli olarak çalışması durumunda yangın ve etkileri en kısa zamanda kontrol altına alınabilir. Yangının oluşma aşamasında hastalarla aynı kat içerisindeki yeterli yangın direncine sahip güvenli alanlara tahliye yapılırsa can ve mal kaybı yaşanmadan ya da daha az zararla atlatılabilir. Hastane binalarında yangın anında kriz yönetimi sağlanamaz ise can ve mal kaybı gibi büyük felaketler yaşanabilir.

Hastane yangınlarının çıkış başlıca sebepleri aktif yangın algılanma ve söndürülme sistemlerindeki eksiklikler, yatay tahliye alanlarının olmaması ve hastane çalışanlarının yangın eğitimlerine katılmamasıdır. Ülkemizde 2007-2018 yılları arasında 105 hastane yangını yaşanmıştır. Bu çıkan yangınların 34 tanesi üniversite araştırma hastanelerinde, 52 tanesi devlet hastanelerinde ve 19 tanesi ise özel hastanelerde meydana gelmiştir. 2017 itibariyle toplam hastane sayısı 1.518'nın 879'u devlet hastanesi, 571'i özel hastane ve 68'i üniversite araştırma hastanesidir. Bu verilerden görüldüğü üzere üniversite araştırma hastanelerinde daha fazla yangın çıkmaktadır.

\section{Hastane Yangınları ve Nedenleri}

Ülkemizde yaşanan hastane yangınları için güvenli bir veri tabanı oluşturulmamıştır. ABD’de National Fire Incident Reporting System (NFIRS) çok eskiden beri yangınların her kategoride ayrıntılı bir şekilde istatistiklerinin çıkarılması için bir veri tabanı oluşturulmuştur. National Fire Protection Association Fire Analysis and Research Division gibi araştırma kuruluşları bu veri tabanlarını kullanarak güvenilir sonuçlar elde etmişlerdir. Bu kuruluşların ABD'deki 2003 2006 yılları arasındaki verileri kullanarak hastane yangınlarını çıkış nedenlerini aşağıdaki Şekil 1'de verilmiştir (İnce 2016).

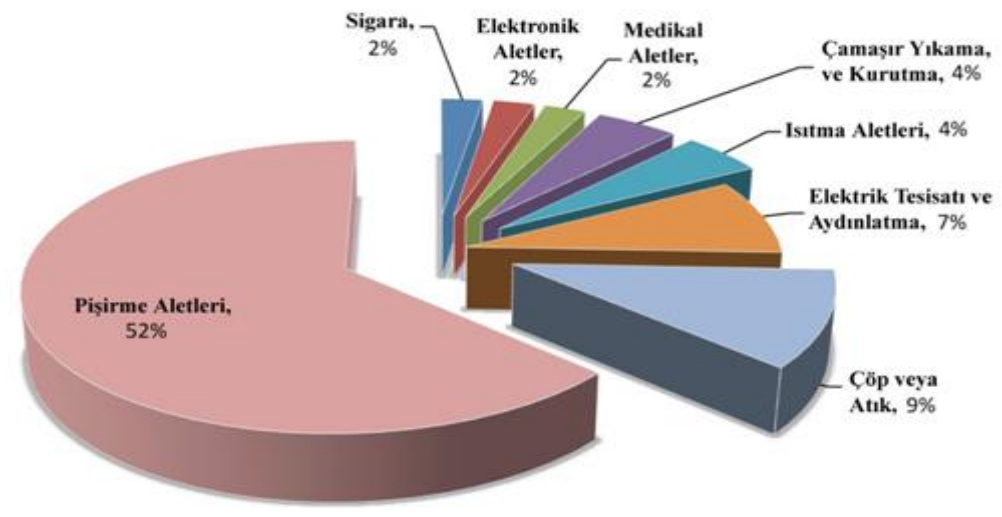

Şekil 1: Hastanelerde meydana gelen yangınlarının oluştukları mekânlar (İnce 2016)

$\mathrm{Bu}$ verilerden elde edilen sonuçlar göre hastanelerde oluşan yangınların yarısı pişirme işlemleri sırasında yaşanmaktadır. Diğer yangını tetikleyen faktörler ise sırasıyla elektrik tesisatı ve elektrikli aletler, 1sıtma işlemleri, çamaşır yıkama, kurutma bölümleri ve sterilizasyon işlemlerinden kaynaklanmaktadır. Medikal ve elektronik aletlerin yangınlara sebebiyet verdiği, sınırlandırılsa da dikkatsizlik, sigara hastane yangınlarına neden olmaktadır. 
Hastanelerde çöplerin, tıbbi ve evsel atıkların da yangına neden olduğu için kontrol altına alınması gerekir (İnce 2016; URL-1 2019). Hastane binalarında, yangınların \%53'ünün hizmet bölümlerinde, \%22'sinin özel bölümlerde, \%10'unun hasta bakım bölümlerinde ve diğer kısım ise destek bölümlerde çıkmaktadır. Yangının erkenden algılanması ve kontrollü söndürülmesi, can ve mal kaybını önlemek veya zararları en az seviyeye indirmektedir (Şimşek ve Akıncıtürk 2016).

Bütün bu yangınlar, hastaneler için vazgeçilmez olan aktif yangın güvenlik sistemlerinin yetersizliği veya bu sistemlerin olmamasından kaynaklanmaktadır. Yangına ilk anda müdahale edecek olan önlemlerin olmaması kaçınılmaz felaketler doğurmaktadır. Campbell (2007) tarafından yapılan çalışmaya göre ise hastane yangınlarının nedenleri Şekil 2'de verilmiştir.

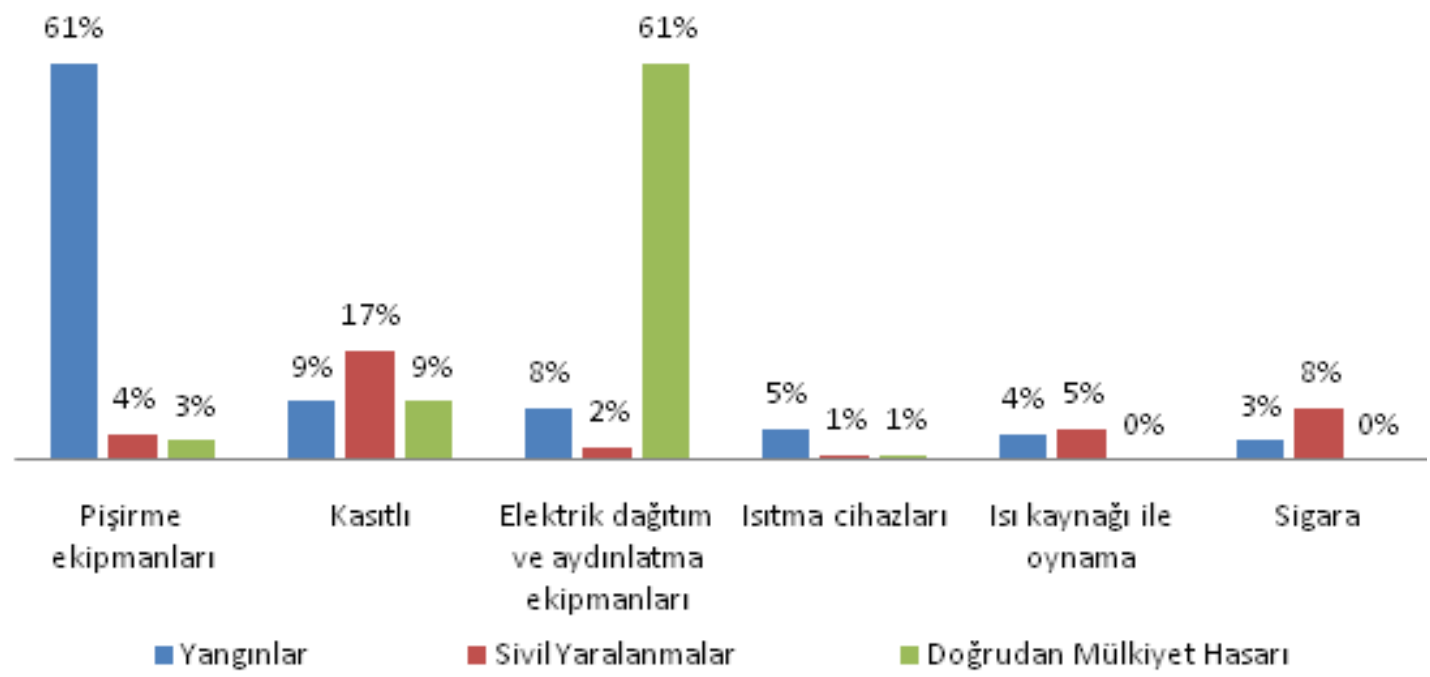

Şekil 2:Hastane yangınlarının başlıca nedenleri 2011-2015 yıllık ortalamaları (Campbell 2007)

Şekle göre hastanelerde yangınların en büyük nedeni \%61 ile pişirme ekipmanları olurken, hastane yangınlarının \%9'u kasten, \%8'i elektrik dağıtımı ve aydınlatma ekipmanları, \%5'i ısıtma cihazları, \%4'ü ısı kaynağı ile oynama ve \%3'ü de sigara nedeniyle çıkmaktadır. Pişirme ekipmanlarından kaynaklana yangınlar, doğrudan mülkiyet hasarının sadece \%3'ünü oluşturmaktadır. Elektrik dağıtım ve aydınlatma ekipmanlarının neden olduğu yangınlar ise doğrudan mülkiyet hasarının \%61'ini oluşturmaktadır (Campbell 2007).

\subsection{Hastanelerde Yangınların Meydana Geldiği Bölümler}

Büyük ve ölümlü hastane yangınları incelendiğinde çıkan yangınların nedeni patlayıcı ve yanıcı kimyasalların bulunduğu ortamlar ve yüksek yangın yüküdür. Ameliyathane, radyasyon, onkoloji, nükleer tıp, gaz merkezi bölümleri direk olarak dış çevreye açılması hasta ve çalışanların güvenliği sağlanmalıdır. Özellikle ameliyathaneler zemin katta bulunmalıdır. Kan alma merkezi acil durum kapısına 9 metre, binanın dış çevreye açılan kapısına ise 15 metre mesafede olacak şekilde tasarlanmalıdır. Bu mesafeler ile bina birkaç dakika içinde boşaltılabilir olmaktadır. Patoloji ve laboratuvarları yanıcı, patlayıcı, parlayıcı kimyasal maddeleri içeren bölümlerdir. Ayrıca röntgen, ultrason, radyasyon, onkoloji, nükleer tıp, teknik servis, yemekhane yangına neden olan mekanlar arasında sayılmaktadır. Yoğun bakım, psikiyatri polikliniklerinde yatan hastalar yangını fark etseler bile harekete geçmeleri zor olmaktadır. Bu bölümlerin çıkış kapıları direk olarak dış ortama açılmalıdır. Nükleer tıp, röntgen, ultrason, radyasyon, onkoloji, çocuk ve genel acil, merkez laboratuvarları, kan sterilizasyon merkezlerinde kullanıcıların yoğun olduğu mekanlar arasındadır, bu bölümler çıkıș kapısına yakın olmalı ve birden fazla çıkış yolu olmalıdır. Tüm görüntüleme mekânları için $24-25^{\circ} \mathrm{C}$ sıcaklık ve \%40-50 bağıl nem olmalıdır. Bu mekânlarda hava iyonize olarak zararlı gazlardan oluşmaktadır. Sıcaklığın $24-27^{\circ} \mathrm{C}$ üzerine çıkması yangına neden olmaktadır. Bu mekânların soğuması ve içeride bulunan zararlı gazların tahliyesi gerekmektedir. Hastanelerde dekor amaçlı kullanılan ahşap asma tavanlar tüm yapı içinde yangın riskini arttırmakta ve yangının ilerlemesini hızlandırmaktadır. Patoloji laboratuvarlarında uçucu gazlar ve kimyasal maddelerin varlığı yangına sebebiyet vermektedir. Yangın riskini düşürmek amacıyla havalandırma boşluğuna yerleştirilen fanlar tarafından ortam sürekli olarak havalandirılmalıdır.

Röntgen, ultrason, tomografi ve monografi bölümlerinde ise yüksek 1Sı yayan cihazlar bulunmaktadır. Görüntüleme maksatlı kullanılan bu bölümlere birçok hasta sevk edilip tedavi edilmektedir. Bu sebepten dolayı kullanıcı yükü bakımından fazladır. Bu bölümler zemin katta bulunmalı ve ameliyathane, yoğun bakım, yataklı klinikler ile düşey ve yatayda yakın ilişkide bulunmamalıdır. 
Pişirme işlemlerinin yapıldığı mutfakta kızgın yağlar, fritöz ve firınlar ayrı bir yangın tehlikesi doğurmaktadır. Yağ damlacıkları ve buharları davlumbaz kanallarına birikmesinden dolayı yangın çıkmaktadır. Isıtma işlemi için kullanılan kazan daireleri, trafo merkezleri, elektrik panoları, medikal gaz odaları, klima santralleri, tıbbı atık odaları ve jeneratör odası yangın tehlikesi taşımaktadır. Hastanede yangın riski olmayan bölüm bulunmamaktadır. Hastanede bulunan bölümlerin yangın risklerine göre gruplandırması aşağıdaki Tablo 1'de verilmiştir (Şimşek 2013).

Tablo 1: Hastanede bölümlerinin yüksek yangın risklerine göre gruplandırması (Şimşek 2013)

\begin{tabular}{|c|c|c|c|c|}
\hline $\begin{array}{l}\text { Yangın } \\
\text { Riski }\end{array}$ & $\begin{array}{l}\text { 1. Derece } \\
\text { yangIn riski }\end{array}$ & $\begin{array}{l}\text { 2. Derece } \\
\text { yangın riski }\end{array}$ & $\begin{array}{l}\text { 3. Derece } \\
\text { yangın riski }\end{array}$ & $\begin{array}{l}\text { 4. Derece } \\
\text { yangin riski }\end{array}$ \\
\hline $\begin{array}{l}\text { Hastane } \\
\text { bölümleri }\end{array}$ & $\begin{array}{l}\text { Röntgen, } \\
\text { Acil röntgen, } \\
\text { Ultrason, } \\
\text { Tomografi, } \\
\text { Mamografi, } \\
\text { Klima santrali }\end{array}$ & $\begin{array}{l}\text { Radyoloji, radyasyon } \\
\text { onkoloji poliklinikler, } \\
\text { EEG-EMG } \\
\text { laboratuvarı, } \\
\text { FTR uygulama }\end{array}$ & $\begin{array}{l}\text { Adli tıp } \\
\text { Hemodiyaliz } \\
\text { Sterilasyon, } \\
\text { Kan merkezi. }\end{array}$ & $\begin{array}{l}\text { Genel ve klinik yoğun } \\
\text { bakımları, } \\
\text { Ameliyathaneler, } \\
\text { Plastik cerrahi ve } \\
\text { yanık merkezi, } \\
\text { Klinikler }\end{array}$ \\
\hline
\end{tabular}

Yangın riski yüksek olan 1. ve 2. derece yangın riski olan bazı bölümler yapı dışına alınması gerekmektedir. 1. derece yangın riski olan oksijen merkezi, patoloji, atölyeler, kazan dairesi, 1sıtma merkezidir. 2. derece yangın riski olan merkez laboratuvarı eczane arşiv, depo, yemekhane, teknik servis, eşanjör ve nükleer tıptır. Yangın için özel bir düzenleme gerektirmeyen mekânlar poliklinikler, fiziksel tıp, rehabilitasyon merkezi spor hekimliği, morg, idari bölüm, enfeksiyon, acil çocuk, acil tüp merkezi ve kadın doğum ünitesidir (Şimşek 2013).

Hastaneler bölüm ve fonksiyonlarına göre 4 bölümde sınıflandırmıştır (Şekil 3). Yapılan sınıflandırmaya göre hastane binalarında idari birimler, muayene tanı ve tedavi birimleri, teşhise yardımcı birimler ve servis birimlerinden oluşmaktadır (Harputlugil 2005).

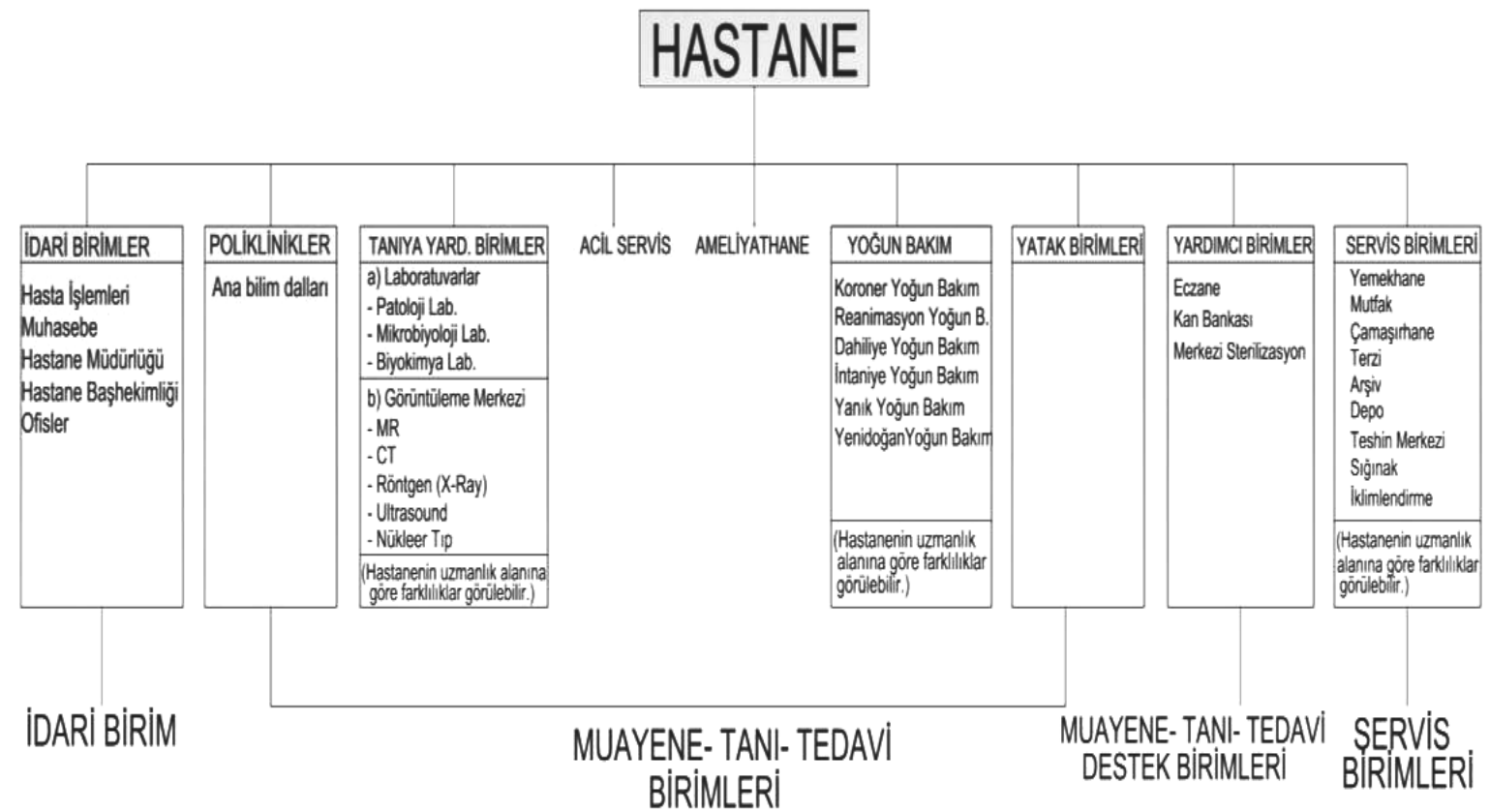

Şekil 3: Hastane binalarında bulunan mekânlar (Harputlugil 2005)

\subsection{Dünyada Yaşanan Bazı Önemli Hastane Yangınları}

1929'dan beri farklı ülkelerde yaşanmış ve tarihe geçmiş önemli 24 hastane yangını meydana gelmiştir. Yangın sırasında gelişen olaylar, söndürme teknikleri ve tahliye çalışmaları incelenmiş ve yangın anındaki can kaybı Tablo 2'de verilmiştir (Şimşek ve Akıncıtürk 2016). 2000'li yıllardan önce tarihte yaşanmış en büyük hastane yangınları akıl hastanelerinde yaşanmış ve bu yangınların çıkmasına genellikle hastalar neden olmuştur. Tarihe geçmiş en büyük akıl hastanesi yangınları arasında Guatemala Akıl Hastanesi ve Cleveland hastanesi yer almaktadır. Bu yangınların nedeni tasarım ilkeleri, yangın algılama ve söndürme sistemleri gibi teknolojik uygulamaların eksikliklerinden kaynaklanmıştır (Cote ve Linville 1997; Shastri vd. 2018). 
Tablo 2: Ölümle sonuçlanan bazı büyük hastane yangınları (Şimşek ve Akıncıtürk 2016)

\begin{tabular}{|c|l|l|c|}
\hline Yll & \multicolumn{1}{|c|}{ Hastane } & Ülke & Ölüm \\
\hline 1929 & Ak1l Hastanesi & Amerika Bileşik Devletleri & 125 \\
\hline 1942 & Ak1l Hastanesi & Yeni Zelanda & 37 \\
\hline 1949 & St. Anthony's Hastanesi & Amerika Bileşik Devletleri & 74 \\
\hline 1950 & Mercy Hastanesi & Yeni Zelanda & 41 \\
\hline 1960 & Ak1l Hastanesi & Guatemala & 235 \\
\hline 1961 & Hartford Hastanesi & Amerika Bileşik Devletleri & 16 \\
\hline 1971 & Ak1l Hastanesi & İviçre & 28 \\
\hline 1974 & Missouri Hastanesi & Amerika Bileşik Devletleri & 8 \\
\hline 1986 & California Hastanesi & Amerika Bileşik Devletleri & 5 \\
\hline 1993 & New York Hastanesi & Amerika Bileşik Devletleri & 3 \\
\hline 1994 & Virginia Hastanesi & Amerika Bileşik Devletleri & 6 \\
\hline 1998 & Manila Hastanesi & Filipinler & 20 \\
\hline 1999 & Leningrad Oblast Hastanesi & Rusya & 21 \\
\hline 2000 & Fire in Beijing Hastanesi & Çin & 3 \\
\hline 2003 & Kozlovichi Ak1l Hastanesi & Belarus & 30 \\
\hline 2005 & Liaoyang Hastanesi & Çin & 33 \\
\hline 2005 & Irak Hastanesi & Irak & 12 \\
\hline 2005 & CalderónGuardia Hastanesi & San Jose, Costa Rica & 19 \\
\hline 2006 & Moscow Hastanesi & Rusya & 42 \\
\hline 2006 & China Hastanesi & Çin & 27 \\
\hline 2009 & StJude Hastanesi & St. Lucia, Karayipler & 3 \\
\hline 2011 & Amri Hastanesi & Kolkata, Hindistan & 91 \\
\hline 2013 & Ak1l Hastanesi & Ramensky, Rusya & 38 \\
\hline 2013 & Ak1l Hastanesi & Novgorod, Rusya & 27 \\
\hline 2015 & Jizan Hastanesi & Suudi Arabistan & 25 \\
\hline 2015 & Ak1l Hastanesi & Rusya & 9 \\
\hline 2018 & Taipei Hastanesi & Tayvan & 6 \\
\hline 2018 & Miryang Hastanesi & Güney Kore & 23 \\
\hline 2018 & Numbai Hastanesi & Hindistan & \\
\hline
\end{tabular}

Tablo 2'de görüldüğü üzere dünya da meydana gelen hastane yangınları en fazla Amerika Bileşik Devletlerinde yaşanmıştır. ABD itfaiye bölümlerine yılda ortalama 7100 hastane yangının söndürüldüğ̈ü, bu yangınlarda yılda ortalama 5 kişinin ölümüne neden olduğu bilinmektedir. 2006-2010 yılları arasında ise yılda ortalama 1400 hastane yangınına müdahale edildiği, bu yangınlarda ise yılda ortalama sadece bir ölümle sonuçlandığı raporlanmıştır. Yapılan araştırmalarda hastane yangınları sayısında ve ölümlerin azalmasındaki temel nedenleri arasında otomatik yangın algılama ve söndürme sistemleri yer almaktadır (İnce 2016).

Bütün hastane yangınlarının incelenmesi durumunda, farklı fonksiyona sahip hastanelerde yangının çıtığı bölüm ve nedenleri arasında farklılık çıkmaktadır. Yangın yükü, mekânın kullanım amacı ve yangın güvenlik önlemleri bu olasılığı artıran dış faktörlerdir. Şekil 4'de hastanelerde yangınların meydana geldiği bölümler verilmiştir. Hastanelerde yangının en fazla \%17 ile hasta odası ve ofislerde, \%13 ile kazan dairesi ve çatıda, \%8 ile trafo merkezi ve kantinde, \%4 ile kan alma merkezi, çamaşırhane, arşiv ve tomografi merkezinde yangın çıkmıştır (Şimşek ve Akıncıtürk 2016).

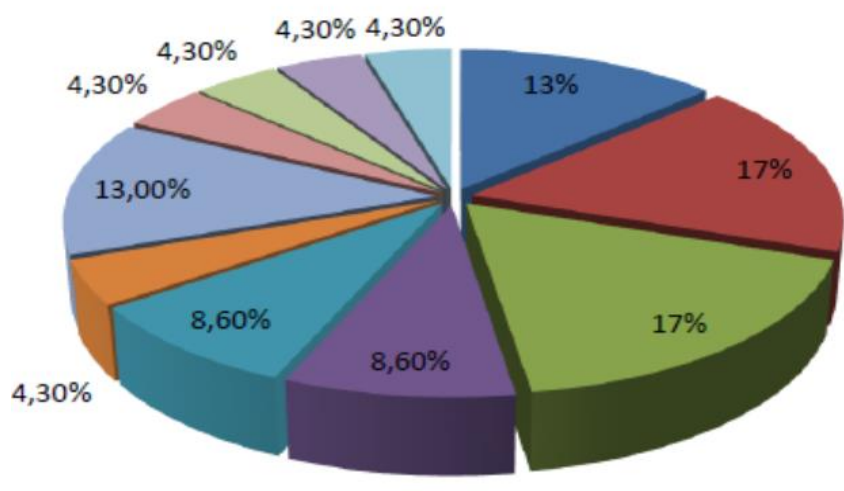

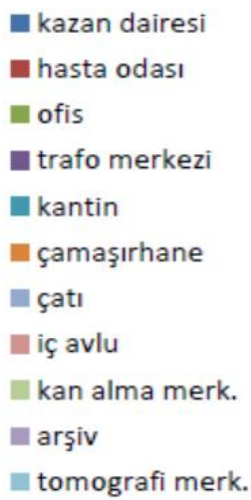

Şekil 4: Hastanelerde Yangınların Meydana Geldiği Bölümler (Şimşek ve Akıncıtürk 2016) 


\subsection{Türkiye'deki Hastane ve Yatak Sayısı}

Türkiye'de sağlık 1982 yılına kadar devlet tarafında sunulması gereken bir hizmet olarak kabul edilmiştir. 1990'lardan itibaren Türkiye'de özel sağlık hizmet sunan hastanelerin sayısı da hızla artmaktadır. Türkiye'de sağlık sektörü, 1980'lerden sonra 3 kat daha büyümüştür. 2017 yılında toplam hastane sayısı 1.518 oldu. 2017 yılında Türkiye genelinde sunulan sağlık hizmetinin \%58 Sağlık Bakanlığg hastanesi, \%38 Özel hastaneler ve \%4'ü ise üniversite hastanelerine aittir (HASUDER 2014; URL-2 2017).

Tablo 3: Sektörlere Göre Hastane Sayısı

\begin{tabular}{|l|c|c|c|c|}
\hline \multicolumn{1}{|c|}{ Bölge adı } & Sağlık Bakanlı̆̆ & Üniversite & Özel & Toplam \\
\hline İstanbul & 54 & 16 & 168 & 238 \\
\hline Batı Marmara & 54 & 4 & 21 & 79 \\
\hline Ege & 118 & 7 & 69 & 194 \\
\hline Doğu Marmara & 80 & 4 & 51 & 135 \\
\hline Batı Anadolu & 70 & 13 & 52 & 138 \\
\hline Akdeniz & 81 & 8 & 88 & 177 \\
\hline Orta Anadolu & 72 & 4 & 23 & 99 \\
\hline Batı Karadeniz & 96 & 3 & 20 & 119 \\
\hline Doğu Karadeniz & 67 & 1 & 11 & 79 \\
\hline Kuzeydoğu Anadolu & 52 & 2 & 5 & 59 \\
\hline Ortadoğu Anadolu & 54 & 3 & 16 & 73 \\
\hline Güneydoğu Anadolu & 78 & 3 & 47 & 128 \\
\hline Türkiye & 879 & 68 & 571 & 1518 \\
\hline
\end{tabular}

2017 yılında toplam hastane yatak sayısı 225.863 olmuştur. Bu hastanelerin \%60 sağlık bakanlığına\%22 özel hastane ve \%18 üniversite hastanelerine aittir. Her ne kadar üniversite hastanelerinin sayısı az da olsa hasta yatağ sayısı dikkate alındığında önemli ölçüde yer almaktadır (URL-2 2017).

Tablo 4: Sektörlere göre hasta yatak sayısı

\begin{tabular}{|l|c|c|c|c|}
\hline \multicolumn{1}{|c|}{ Bölge adı } & Sağlık Bakanlığı & Üniversite & Özel & Toplam \\
\hline İstanbul & 17.7783 & 5.423 & 14.748 & 37.954 \\
\hline Batı Marmara & 6.662 & 1.868 & 1.724 & 10.214 \\
\hline Ege & 18.599 & 5.628 & 5.686 & 29.913 \\
\hline Doğu Marmara & 12.930 & 2.796 & 3.678 & 19.404 \\
\hline Batı Anadolu & 14.167 & 7.262 & 4.570 & 25.998 \\
\hline Akdeniz & 16.829 & 5.186 & 7.300 & 29.315 \\
\hline Orta Anadolu & 7.127 & 2.879 & 1.964 & 11.970 \\
\hline Batı Karadeniz & 10.401 & 2.114 & 1.838 & 14.353 \\
\hline Doğu Karadeniz & 6.643 & 831 & 1.149 & 8.623 \\
\hline Kuzeydoğu Anadolu & 4.402 & 1.193 & 319 & 6.414 \\
\hline Ortadoğu Anadolu & 7.467 & 2.772 & 1.277 & 11.516 \\
\hline Güneydoğu Anadolu & 12.369 & 2.872 & 4.947 & 20.188 \\
\hline Türkiye & 135.339 & 41.324 & 49.200 & 225.863 \\
\hline
\end{tabular}

\section{3. Ülkemizde Yaşanan Hastane Yangınları}

Sağlık hizmeti sunan kurum ve kuruşların en temel özelliği, birden fazla birimi tek çatı altında toplayan karmaşık yapıya sahip olmalarıdır. Bu özelliğinden dolayı bazı büyük tehlike ve riskleri beraberinde getirmektedir. Bu tehlikelerin en büyüğü ve hastaneler için kaçınılmaz olanı yangın tehlikesidir. Yangın tehlikesinin maddi ve manevi zararlarının geri dönüşümü yoktur. Hastaneler için yangın her an her yerde karşımıza çıkabilmektedir. Bütün sağlık kuruluşlarında kişinin tanı ve tedavisin yanı sıra can güvenliği korumak temel görevler arasında yer almaktadır. Ülkemizde 2007-2018 yılları arasında 105 tane hastane yangını yaşanmıştır. Bunların 34 tanesi üniversite hastanelerinde, 52 tanesi devlet hastanelerinde ve son olarak 19 tanesi özel hastanelerde yaşanmıştır. Üniversite hastanesi ve özel hastanelerde ölümlü yangın olayı yaşanmamıştır. Devlet hastanelerinde çıkan yangınlar sonucu hasta ve hastane personeli hayatını kaybetmiştir. Bu hastane yangınları, maddi ve manevi büyük zararlara yol açmıştır. 
Yangının hastane içerisinde çıktığı bölüm farklılık gösterse de yaşanan yangınların temel nedeni elektrik ve dikkatsizliktir. Yangın anındaki kayıpların asıl sebeplerinden biri yangına ilk olarak müdahale edecek aktif yangın algılanma ve söndürülme sistemlerinin eksikliğidir.

Ülkemizde yaşanan en fazla can kaybı yaşanan hastane yangını 26 Mayıs 2009 gecesi saat 02.00 sıralarında Bursa Şevket Yılmaz Devlet Hastanesinde yaşanmıştır. Bu hastane yangını ikinci bodrum katında tomografi cihazındaki elektriksel ısınmadan dolayı çıkmıştır ve 11 yoğun bakım hastası hayatını kaybetmiştir (Şimşek ve Akıncıtürk 2016). Diğer en fazla can kaybının yaşandığı hastane yangını ise 18 Haziran 2018 saat 04.00 sıralarında, Gaziantep'te bulunan NCR International Hospital'da meydana gelmiştir. Yangın, hastanenin bodrum katındaki enerji depolama odasında, aşırı 1sınmadan dolayı çıkmıştır. Bunun sonucu olarak 2 yoğun bakım hastası yaşamını yitirmiştir. Ülkemizde son 20 yılda yaşanan hastane yangınlarının nedeni incelendiğinde yangına neden olan durumlar aşağıdaki şekilde sıralanmıştır (Campbell 2007);

- Tibbı cihaz ve ekipmanlardaki arıza,

- Uygun olmayan tıbbi alet kullanımı,

- Elektrik arızaları ve aşırı ısınma,

- Laboratuvarlarda bulunan parlayicı ve patlayıcı maddeler,

- Trafo ve isinma merkezi patlamaları,

- Sigara, dikkatsizlik, sabotaj

- Tadilat çalışmaları

Yangının hastane içerisinde çıktığı bölüm farklılık gösterse de yaşanan yangınların temel nedeni elektrik ve dikkatsizliktir. Yangın anındaki kayıpların asıl sebeplerinden biri yangını aktif yangın algılanma ve söndürülme sistemlerinin eksikliği, düşey tahliye alanlarının olmaması, hastane binasının yer seçiminin doğru olmaması ve hastane personelinin yangın eğitimlerine katılmamasıdır.

\section{1. Ülkemizde Yaşanan Özel Hastane Yangınları}

İnsanların sağlıklı ve dengeli yaşaması gün geçtikte zorlaşmaktadır. Bu noktada sağlık hizmeti alması zorunlu hale gelmektedir. Temel ve koruyucu sağlık hizmetleri devlet tarafından verilirken tedavi ve iyileştirme sağlık hizmetleri piyasa ekonomisine bırakılmıştır. Özel hastaneler, devlete ait olmayan gerçek kişiler ve özel hukuk tüzel kişilere ait hastanelerdir. Özel sektörlerde yer alan sağlık kurumları hastaların tedavi süreçlerinde önemli hale gelmiştir. Özellikle 2002 yılı itibariyle son 10 yılda özel hastanelerin ve kuruluşların sayısı artmaktadır. Özel hastaneler olan yatırım ülkemizde giderek artmaktadır (HASUDER 2014; URL-2 2017). 2017 yılında Türkiye'de 571 özel hastane ve 49.200 yatak bulunmaktadır (URL-3 2018). Özel hastanelerin sayısının artması ile sağlık hizmetinin sunumundaki etkinlik ve verimlilik artmaktadır (URL-3 2018; URL-2 2017) .2017 yılında ülkemizde 571 tane özel hastane bulunmaktadır. 20072018 yılları arasında çıkan hastane yangınlarının 19 tanesi özel hastanelerde yaşanmıştır. Bu çıkan yangınların \%40’lık büyük bir kısmı elektrik kaynaklı, \%30 dikkatsizlik, \%25 tadilat çalışmasında ve \%5'lik kısmı ise arşiv bölümünden kaynaklanmakta ve Şekil 5'te gösterilmiştir.

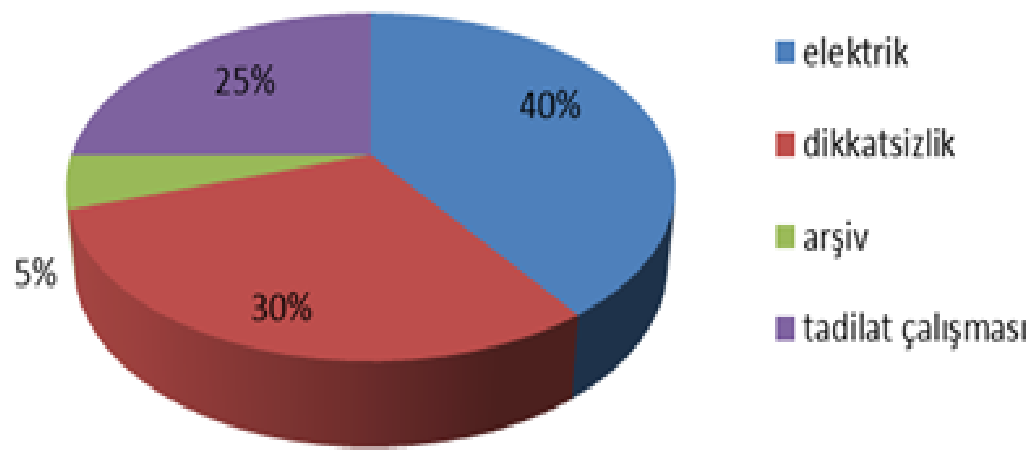

Şekil 5: 2007-2018 yılları arası yaşanan özel hastane yangınlarının nedenleri

Ülkemizde 2007-2018 yılları arasında çıkan özel hastane yangınlarında can kaybı yaşanmamıştır. Sadece maddi kayıplar yaşanmıştır. 2007-2018 yılları arasında ülkemizde yaşanan özel hastane yangınları aşağıdaki Tablo 5'de verilmiştir. 
Tablo 5: 2007-2018 yılları arasında yaşanan özel hastane yangınları

\begin{tabular}{|c|l|l|l|}
\hline Yıl & \multicolumn{1}{|c|}{ Şehir } & \multicolumn{1}{|c|}{ Hastane } & \multicolumn{1}{c|}{ Yangının çıkma nedeni } \\
\hline 2007 & İstanbul & İstanbul Cerrahi Hastanesi & İzolasyon malzemelerinin tutuşması \\
\hline 2008 & Batman & Batman Özel Hastanesi & Yangın nedeni tespit edilmemiştir \\
\hline 2009 & Adana & Adana Özel Hastanesi & Yangın nedeni tespit edilmemiştir \\
\hline 2010 & Bursa & Özel Onkoloji Hastanesi & Elektrik panosu \\
\hline 2010 & İstanbul & Florence Nightingale Hastanesi & Elektrik trafosu \\
\hline 2011 & İstanbul & Medical Park Hastanesi & Plastik malzemelerin tutuşması \\
\hline 2011 & İstanbul & Ümraniye Özel Erdem Hastanesi & İzolasyon çalışması \\
\hline 2012 & İstanbul & Drogos Şifa Hastanesi & Elektrik kontağ1 \\
\hline 2013 & Diyarbakır & Veni Vidi Hastanesi & Yangın nedeni tespit edilmemiştir \\
\hline 2013 & Gaziosmanpaşa & Şafak Hastanesi & Kısa devre \\
\hline 2014 & İstanbul & Beyoğlu'nda Özel Bir Hastane & Yangın nedeni tespit edilmemiştir \\
\hline 2014 & Afyon & Afyonda Özel Bir Hastane & Yangın nedeni tespit edilmemiştir \\
\hline 2016 & İstanbul & Bahçelievler'de Özel Bir Hastane & Elektrik kaynaklı \\
\hline 2016 & Samsun & Medical Park & Yangın nedeni tespit edilmemiştir \\
\hline 2017 & İstanbul & Gebze'de Özel Bir Hastane & Elektrik panosu \\
\hline 2018 & Gaziantep & NCR Özel Hastanesi & Aşırı 1sınma \\
\hline 2018 & İstanbul & Sultanbeyli'de Özel Hastane & Yangın nedeni tespit edilmemiştir \\
\hline 2018 & Malatya & Malatya'da Özel Bir Hastane & Yangın nedeni tespit edilmemiştir \\
\hline 2018 & İstanbul & Pendik’te Özel Hastane & Yangın nedeni tespit edilmemiştir \\
\hline
\end{tabular}

\title{
3.2. Ülkemizde Üniversite Araştırma Hastanelerinde Yaşanan Yangınlar
}

Ülkemizde 2007-2018 yılları arasında çıkan hastane yangınlarının 34 tanesi üniversite araştırma hastanelerde çıkmıştır. $\mathrm{Bu}$ yangınların büyük çoğunluğu elektrikten kaynaklanmaktadır. Yaşanan yangınların diğer sebepleri ise tamirat çalışmaları, arşiv odası, medikal gaz ve vakum odaları, tıbbı atık odası, oksijen ve nitrojen tüplerinin patlaması, sigara ve trafo patlaması ve dikkatsizlikten dolayı çıkmıştır. Çıkan yangınlarda can kaybı yaşanmamıştır. Ancak yüksek maliyetli hasarlar olmuştur.2007-2018 yılları arasında ülkemizde üniversite hastanelerinde yaşanan yangınlar Tablo 6'da verilmiştir.

2017 yılı itibariyle ülkemizde 68 tane üniversite hastanesi ve 41.324 tane hasta yatağ bulunmaktadır. 2007- 2018 yılları arasında yaşanan 105 yangından 34 tanesi üniversite hastanelerinde yaşanmıştır. Ülkemizde var olan 68 tane üniversite hastanesinden 34'ünde yangın çıkmıştır, başka bir deyişle her iki üniversite araştırma hastanesinden birinde yangın çıkmıştır. Bunun nedeni ise üniversite hastanelerinin büyük ve kalabalık yapısından kaynaklanmaktadır. Özel hastane ve devlet hastanesinde çıkan yangınlara göre kıyaslandığında çıkan yangınların büyük bir kısmı üniversite araştırma hastanelerinde yaşanmıştır.

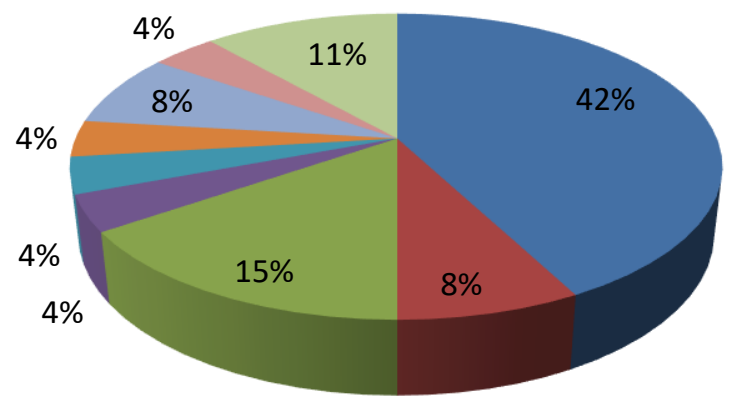

\author{
elektrik \\ trafo patlaması \\ dikkatsizlik \\ arşiv \\ yemekhane \\ çamaşırhane \\ tıbbı atık odası \\ oksijen tüpü \\ sigara
}

\section{Şekil 6: 2007-2018 yılları arası yaşanan üniversite hastane yangınlarının nedenleri}

Üniversite hastanesinde çıkan yangınların nedeni ise \%42'lik büyük kısmı elektrik kaynaklı, \%15 dikkatsizlik, \%11 sigara, \%8 trafo patlaması ve tıbbı atık odasından kaynaklanmakta, \%4'lük kısmı ise yemekhane, çamaşırhane, oksijen tüpü ve arşiv bölümünde yaşanmaktadır. 
Tablo 6: 2007-2018 yılları arasında yaşanan üniversite hastanesi yangınları

\begin{tabular}{|c|c|c|c|}
\hline Yil & Şehir & Hastane Adı & Yangın Çıkma Nedeni \\
\hline 2007 & İstanbul & Cerrahpaşa Tıp Fakültesi & Çatı katında nedeni tespit edilmemiştir \\
\hline 2008 & Trabzon & Karadeniz Teknik Üniversitesi Tıp Fakültesi & Elektrik kontağı. \\
\hline 2008 & Manisa & Celal Bayar Üniversitesi Tıp Fakültesi & Elektrik kontağ1 \\
\hline 2009 & İstanbul & Cerrahpaşa Tıp Fakültesi & Tadilat çalışması \\
\hline 2009 & Manisa & Celal Bayar Üniversitesi Tıp Fakültesi & Kisa devre \\
\hline 2009 & İstanbul & Çapa Tıp Fakültesi & Elektrik kontağ 1 \\
\hline 2009 & İstanbul & Marmara Üniversitesi Tıp Fakültesi & Yangın nedeni tespit edilmemiştir \\
\hline 2010 & Edirne & $\begin{array}{l}\text { Trakya Üniversitesi Tıp } \\
\text { Fakültesi }\end{array}$ & Elektrik kontağ1 \\
\hline 2010 & Samsun & 19 Mayıs Üniversitesi Tıp Fakültesi & Hasta kaynaklı \\
\hline 2010 & Bursa & Uludağ Üniversitesi Tıp Fakültesi & İzolasyon çalışması \\
\hline 2011 & Adana & Çukurova Üniversitesi Tıp Fakültesi & Tadilat çalışması \\
\hline 2011 & İstanbul & Çapa Tıp Fakültesi & Arşivde yangın nedeni tespit edilmemiştir \\
\hline 2011 & Antalya & Akdeniz Üniversitesi Tıp Fakültesi & Elektrik kabloların alev alması \\
\hline 2012 & Bursa & Uludağ Üniversitesi Tıp Fakültesi & Nedeni belli değil. \\
\hline 2012 & Erciyes & Erciyes Üniversitesi Tıp Fakültesi & Oksijen tüpünden yangın çıtı. \\
\hline 2014 & Ankara & Ankara Üniversitesi Tıp Fakültesi & Atıkların patlaması sonucu yangın çıktı. \\
\hline 2014 & Hatay & Mustafa Kemal Üniversitesi Tıp Fakültesi & Yangın nedeni tespit edilmemiştir \\
\hline 2014 & İstanbul & Çapa Tıp Fakültesi & $\begin{array}{l}\text { Tıbbı atıkların atıldığı odada nedeni tespit } \\
\text { edilmemiştir }\end{array}$ \\
\hline 2015 & Ankara & Gülhane Askeri Tıp Akademisi & Sigara izmariti \\
\hline 2015 & İstanbul & Cerrahpaşa Tıp Fakültesi & Trafo patlamas1 \\
\hline 2015 & Van & Yüzüncü Yıl Tıp Fakültesi & $\begin{array}{l}\text { Çamaşırhane bölümünde nedeni tespit } \\
\text { edilmemiştir }\end{array}$ \\
\hline 2016 & Ankara & Ankara Üniversitesi Tıp Fakültesi & Elektrik kaynaklı \\
\hline 2016 & Kocaeli & Umut Tepe Tıp Fakültesi & Elektrik kontağ1 \\
\hline 2016 & Antalya & Akdeniz Üniversitesi Tıp Fakültesi & Elektrik kaynakl1 \\
\hline 2017 & Eskişehir & Osmangazi Tıp Fakültesi & Elektrik panosu \\
\hline 2017 & Aydın & Adnan Menderes Üniversitesi Tıp Fakültesi & Elektrik kontağ 1 \\
\hline 2017 & Diyarbakır & Dicle Tıp Fakültesi & $\begin{array}{l}\text { Teknik bakım servisinde nedeni tespit } \\
\text { edilmemiştir }\end{array}$ \\
\hline 2017 & Sivas & Cumhuriyet Üniversitesi Tıp Fakültesi & Yangın nedeni tespit edilmemiştir \\
\hline 2018 & Muğla & Sttk1 Koçman Üniversitesi Tıp Fakültesi & Elektrik kontağ \\
\hline 2018 & Van & Yüzüncü Yı1 Tıp Fakültesi & Trafo ünitesinde nedeni tespit edilmemiştir \\
\hline 2018 & İstanbul & Bezmi Âlem Üniversitesi Tıp Fakültesi & Yangın nedeni tespit edilmemiştir \\
\hline 2018 & İzmir & Kâtip Çelebi Üniversitesi Diş Hekimliği Fakültesi & Otoparkta nedeni tespit edilmemiştir \\
\hline 2018 & İzmir & Ege Üniversitesi Tıp Fakültesi & Yangın nedeni tespit edilmemiştir \\
\hline 2018 & Adiyaman & Adıyaman Üniversitesi Tıp Fakültesi & Elektrik kontağ 1 \\
\hline
\end{tabular}

Üniversite hastanelerinde, sağlık sistemi içerisinde doğrudan hasta tedavisi ve bakımının yanı sıra çeşitli sağlık eğitimi ve tıbbı araştırma faaliyetleri de gerçekleştirilmektedir. Bu yüzden üniversite hastaneleri diğer hastanelere göre daha kompleks ve kalabalıktır. Üniversite hastanelerinde, poliklinikler, derslikler, laboratuvarlar, yemekhane, ofisler, mutfak, kazan dairesi, çatı katı, arşiv, elektrik tesisatı, parlayıcı ve patlayıcı maddeler, oksijen sistemleri gibi birçok mekân tek çatı altında toplanmaktadır. Bununla birlikte üniversite hastanelerinde diğer hastanelere göre çalışan, öğrenci, hasta ve ziyaretçi sayısı daha fazladır. Bu nedenle üniversite hastanelerinde meydana gelebilecek bir yangın, felakete sebep olabilir.

\section{3. Ülkemizde Devlet Hastanelerinde Yaşanan Yangınlar}

Ülkemizde özel sağlık hizmeti sunan hastanelerde yangın güvenlik önlemlerine önem verildiği görülmektedir. Fakat devlet hastanelerinde imkânsızlıklar nedeniyle yangın anında büyük problemler yaşanmaktadır. Devlet hastanelerinde meydana gelen yangınlar, diğer hastanelerde olduğu gibi elektrik kaynaklı yangınlardır. Daha sonra ise dikkatsizlik nedenli yangınlar yaşanmaktadır. Yangın çıktığı bölümler ise farklılık göstermektedir. Çamaşırhane, kantin, mutfak, hasta odası, kazan dairesi çatı katı, depo, bilgi işlem, atık deposu, onkoloji bölümü, otopark, yemekhane, dahiliye, acil servis, NMR ve tomografi odası, ameliyathane, asansör boşluğunda yangın çıkmaktadır. 


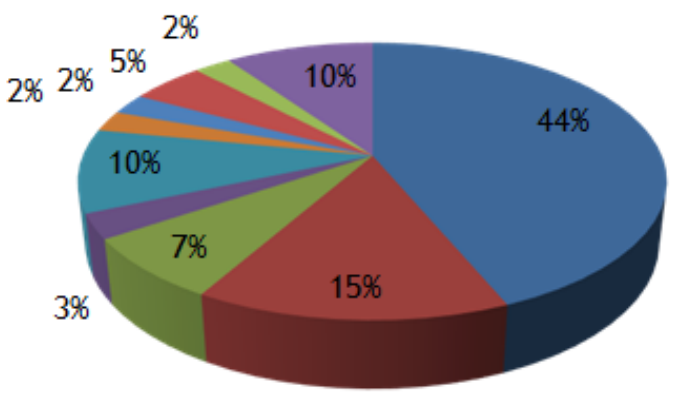

\author{
- elektrik \\ - trafo patlaması \\ n sigara \\ - dikkatsizlik \\ - tıbbı atık odası \\ - depo \\ - çamaşırhane \\ - kantin \\ - tadilat çalışması \\ mutfak
}

\title{
Şekil 7: 2007-2018 yılları arasında yaşanan devlet hastanesi yangınlarının nedenleri
}

2017 yılı itibariyle ülkemizde 879 tane devlet hastanesi bulunmaktadır. 2007-2018 yılları arasında çıkan 105 hastane yangının 52 tanesi devlet hastanelerinde yaşanmıştır. Devlet hastanesinde çıkan yangınlar sonucu can ve mal kaybı yaşanmıştır. Devlet hastanelerinin sayısının ve kullanıcılarının daha fazla olmasından yangın yaşanmaktadır. Devlet hastanesinde yaşanan yangınların nedeni ise \%44'lük büyük kısmı elektrik kaynaklı, \%15 trafo patlaması, \%10 dikkatsizlik ve depo bölümünden kaynaklı, \%7 sigara, \%5 çamaşırhane bölümünden, \%3 dikkatsizlik ve \%2'si ise kantin, tadilat çalışması, mutfak ve tıbbı atık odasından kaynaklanmaktadır. Devlet hastanelerinde aktif yangın engelleme ve söndürme sistemlerinin eksik ya da yetersiz olmasından dolayı yangında can ve mal kaybı yaşanmıştır. Devlet hastanelerindeki yangın güvenlik önlemleri tam olsa bile çalışan personelin eğitim eksikliği ve hastaların tahliyesine yardımcı olacak personelin yeterince bilinçlendirilmesi yangına davetiye çıkarmaktadır.

Tablo 7: 2007-2018 yılları arasında yaşanan devlet hastanesi yangınları

\begin{tabular}{|c|c|c|c|}
\hline Yıl & Şehir & Hastane & Yangının çıkma nedeni \\
\hline 2007 & Mersin & Kadın Doğum Hastanesi & Arızalı çamaşır makinesi \\
\hline 2007 & Ankara & 29 Mayıs Tıp Merkezi & Trafo patlamas1 \\
\hline 2007 & Edirne & Keşan Devlet Hastanesi & Elektrik arızas1 \\
\hline 2007 & Bursa & Mustafa Kemal Paşa Devlet Hastanesi & Mutfak tüpünün alev alması \\
\hline 2007 & Samsun & Ruh Sağlığı ve Hastalıkları Hastanesi & Bir hastanın sigara ile yatak çarşafını yakması \\
\hline 2007 & Samsun & Bafra Devlet Hastanesi & Tadilat çalışması \\
\hline 2007 & İstanbul & Şişli Eftal Hastanesi & Sigara izmariti \\
\hline 2008 & İzmir & Ege Doğum Evi & Yangın nedeni tespit edilmemiştir \\
\hline 2008 & Muş & $\begin{array}{l}\text { Kadın Doğum ve Çocuk Hastalıkları } \\
\text { Hastanesi }\end{array}$ & Isıtma cihazlarından oluşan arıza \\
\hline 2008 & Balıkesir & Ayvalık Devlet Hastanesi & Isıtma cihazlarından oluşan arıza \\
\hline 2008 & Erzurum & Bölge Eğitim ve Araştırma Hastanesi & Açık bırakılan elektrik cihazı \\
\hline 2008 & Edremit & Edremit Devlet Hastanesi & Elektrik panosu \\
\hline 2008 & İstanbul & Tepecik Eğitim Araştırma Hastanesi & Elektrik kontağ 1 \\
\hline 2009 & Bursa & Şevket Y1lmaz Devlet Hastanesi & Elektrik kontağ 1 \\
\hline 2010 & Eskişehir & Yunus Emre Devlet Hastanesi & Bodrum katında nedeni tespit edilmemiştir \\
\hline 2010 & İstanbul & Süreyya Paşa Göğüs Hastalıkları Hastanesi & Çatı katında nedeni tespit edilmemiştir \\
\hline 2010 & Yozgat & Bozok Kadın Doğ. Çocuk Has. & Tesisat arızası \\
\hline 2010 & Kütahya & Çavdarhisar Devlet Hastanesi & Kalorifer dairesinde nedeni tespit edilmemiştir \\
\hline 2011 & Manisa & Selendi Devlet Hastanesi & Elektrik kontağ 1 \\
\hline 2011 & İzmir & $\begin{array}{l}\text { Buca Kadın Doğum Çocuk Hastalıkları } \\
\text { Hastanesi }\end{array}$ & $\begin{array}{l}\text { Tibbı malzemelerin bulunduğu odada nedeni } \\
\text { tespit edilmemiştir }\end{array}$ \\
\hline 2011 & İstanbul & Gazi Osman Paşa Devlet Hastanesi & Dikkatsizlik \\
\hline 2011 & Van & Van Askeri Hastane & Elektrik kontağ \\
\hline 2012 & Bursa & Şevket Y1lmaz Devlet Hastanesi & Elektrik kontağ 1 \\
\hline 2012 & Denizli & Denizli Devlet Hastanesi & Elektrik kontağ \\
\hline 2012 & Ĭgdır & Iğdır Devlet Hastanesi & Yemekhanede gaz kaçağ 1 \\
\hline 2012 & Muş & Kadın Doğum Çocuk Hastalıkları Hastanesi & Yangın nedeni tespit edilmemiştir \\
\hline 2012 & Zonguldak & Ereğli Devlet Hastanesi & Elektrik kontağ 1 \\
\hline
\end{tabular}


Tablo 7'nin Devamı

\begin{tabular}{|c|c|c|c|}
\hline Yll & Şehir & Hastane & Yangının çıkma nedeni \\
\hline 2012 & İstanbul & Ümraniye Eğitim ve Araştırma Hastanesi & Elektrik kontağ1 \\
\hline 2012 & İstanbul & Süreyya Paşa Göğüs Hastalıkları Hastanesi & Elektrik kontağ \\
\hline 2012 & İstanbul & Siyami Ersek Kalp Damar Araştırma Hastanesi & İdari bölümde nedeni tespit edilmemiştir \\
\hline 2013 & Bursa & İnegöl Devlet Hastanesi & $\begin{array}{l}\text { Atıkların geçici olarak depolandığı bölümde } \\
\text { nedeni tespit edilmemiştir }\end{array}$ \\
\hline 2013 & Ardahan & Ardahan Devlet Hastanesi & Elektrik kontağ1 \\
\hline 2013 & Giresun & Giresun Devlet Hastanesi & Elektrik kontağ1 \\
\hline 2014 & Balıkesir & Göğüs Hastalıkları Hastanesi & Yoğun bakım ünitesi \\
\hline 2014 & Aydin & Atatürk Devlet Hastanesi & Elektrik kontağ1 \\
\hline 2014 & İstanbul & Dr. Sadri Konuk Devlet Hastanesi & Elektrik kontağ1 \\
\hline 2014 & Ağr1 & Doğu Beyazıt Devlet Hastanesi & Hastadan kaynaklı \\
\hline 2014 & Kilis & Kilis Devlet Hastanesi & Çatı katında nedeni tespit edilmemiştir \\
\hline 2015 & Ankara & Ulus Devlet Hastanesi & $\begin{array}{l}\text { Yoğun bakım odasında nedeni tespit } \\
\text { edilmemistir }\end{array}$ \\
\hline 2015 & Samsun & Gazi Devlet Hastanesi & Sigara \\
\hline 2015 & Malatya & Malatya Devlet Hastanesi & Hasta odasında nedeni tespit edilmemiștir \\
\hline 2015 & Denizli & Denizli Devlet Hastanesi & Çalıșma sonucu \\
\hline 2015 & Hakkâri & Semdinli Devlet Hastanesi & Klima \\
\hline 2016 & Gaziantep & Dr. Ersin Arlan Eğitim Araștırma Hastanesi & Yangın nedeni tespit edilmemiștir \\
\hline 2016 & İstanbul & Bakırköy Ruh ve Sinir Hastalıkları Hastanesi & Trafo merkezi patlamasi \\
\hline 2016 & K. Maraș & Necip Fazıl Șehir Hastanesi & Elektrik panosu \\
\hline 2016 & İzmir & Alsancak Salih Gören Devlet Hastanesi & Elektrik kabloları \\
\hline 2016 & Bandırma & Bandirma Devlet Hastanesi & İzolasyon çalıșması \\
\hline 2016 & Çanakkale & Lâpseki Devlet Hastanesi & $\begin{array}{l}\text { Çamaşırhane bölümünde nedeni tespit } \\
\text { edilmemistir }\end{array}$ \\
\hline 2016 & İstanbul & Yedikule Göğüs Hastalıkları Has & Elektrik panosu \\
\hline 2017 & Tunceli & Tunceli Devlet Hastanesi & Elektrik kontağ 1 \\
\hline 2017 & Mersin & Anamur Devlet Hastanesi & NMR ve tomografi cihazları \\
\hline
\end{tabular}

\section{Sonuç}

2007-2018 yılları arasında ülkemizde yaşanan yangınlar incelendiğinde en fazla yangının üniversite hastanelerinde ve en az yangının özel hastanelerde çıktığı görülmüştür. Üniversite araştırma hastanelerinin \%50 sinde, devlet hastanelerinin \%6'sı ve özel hastanelerin \%3'ünde yangın meydana gelmiştir. Bu hastane yangınlarının başlıca sebebi \%40-44 oranında elektrik kaynaklıdır. ABD hastanelerinde elektrik kaynaklı yangınların oranı $\% 9$ olup, en fazla yangın pişirme aletlerinden kaynaklanmaktadır. Bu sebeple hastanede bulunan bütün elektrik panoları ve tesisatları termal kamera ile kontrol edilmelidir. Böylece oluşan kıvılcımlar erken tespit edilebilir, yangın önlenebilir. İkinci yangın çıkma sebebi özel ve üniversite araştırma hastanelerinde dikkatsizlik iken devlet hastanesinde trafo arızalarıdır. Ayrıca devlet hastanelerinde ve üniversite araştırma hastanelerinde sigaradan dolayı \% 7-11 arasında yangın çıkarken özel hastanelerde sigara kaynaklı yangın çıkmadığı dikkat çekmiştir.

Hastanelerin yangın önlemlerine göre tasarlanması yangınla mücadele için çok önemli bir husustur. Hastanede öncelikle yangın çıkmaması, yangının başladığının kısa sürede fark edilmesi ve söndürülmesi ile yangının yayılmaması ve büyümemesi sağlanmalıdır. Bunun için aktif ve pasif yangın önlemlerinin alınması gerekir. Hastane yönetim sistemine uygun risk değerlendirmesi yapılmalı, gerek görülen birimlere uygun yangın söndürme ve algılama sistemleri kurulmalıdır.

Hastanede ölü nokta kalmayacak şekilde uygun tipte ve sayıda sesli, 1şıklı veya görsel alarm yangın algılama sistemleri yerleştirilmelidir. Mekânda bulunan bütün yanıcı maddeler, çevre şartları ve kullanıcı profili proaktif yöntemlerle değerlendirilmeli, tüm birimlerde yanıcı maddelerin özelliklerine göre uygun yangın söndürücüler bulundurulmadır. Ayrıca doktorlar, hemşireler ve diğer sağlık personellerine yangın güvenliği ve tahliye üzerine eğitimler verilmelidir. Tüm bu tedbirler alındıktan sonra yangının çıkmasına ya da büyümesinin önüne geçilecek ve kayıplar yaşanmayacaktır.

\section{Kaynaklar}

Başdemir H., Demirel F., (2010), Pasif yangın güvenlik önlemleri bağlamında bir literatür araştırması, Politik Dergisi, 13(2), 101109.

Cambell R., (2007), Structure fires in health care facilities, National Fire Protection Association, https://www.nfpa.org/-/media/Files/ News-and-Research/Fire-statistics-and-reports/Building-and-life-safety/oshealthcarefacilities.pdf, [Erişim 10 Haziran 2019].

Cote A.E., Linville J.L., (1997), Fire Protection handbook, 18thedition, National Fire Protection Association, USA, 2004 ss. 
Harputlugil T., (2005), Yapı elde etme sürecinde tasarım yönetimi-hastane yapılarının ön tasarımında karar alma modeli ve örneklenmesi, Yüksek Lisans Tezi, Gazi Üniversitesi, Fen Bilimleri Enstitüsü, Ankara.

HASUDER, (2014), Türkiye Sağllk Raporu 2014 (TSR 2014), https://sosyolojivefelsefe.files.wordpress.com/2015/01/tc3bcrkiyesac49flc4b1k-raporu-2014.pdf, [Erişim 12 Mayıs 2019].

İnce A., (2016), Hastanelerde yangın güvenliği ve tahliye gerekleri üzerine bir irdeleme, Yüksek Lisans Tezi, Üsküdar Üniversitesi Sağlik Bilimleri Enstitüsü, İstanbul.

Kılıç A., Beceren K., (1999), Mimari tasarımda yangın güvenliği, IV. Ulusal Tesisat Mühendisliği Kongresi ve Sergisi, 4-7 Kasım, İzmir.

Kılıç M., (2003), Yapılarda yangın güvenliği ve söndürme sistemleri, Uludağ Üniversitesi Mühendislik Mimarlık Fakültesi Dergisi, $8(1), 59-70$

URL-1, (2019), Hospital Fires (2012-2014), NFIRS Data Snapshot, https://www.usfa.fema.gov/downloads/pdf/statistics/snapshot_ hospital.pdf, [Erişim 22 Mayıs 2019].

URL-2, (2017), Sağlık Hizmetleri Genel Müdürlüğ̈̈, https://shgm.saglik.gov.tr, [Erişim 12 May1s 2019].

URL-3, (2018), T.C. Sağlık Bakanlı̆̆ı Sağlık İstatistik Yıllı̆̆g, Türkiye Cumhuriyeti Sağlık Bakanlığı Sağlık Bilgi Sistemleri Genel Müdürlüğü, Ankara 2018, https://dosyasb.saglik.gov.tr/Eklenti/31096,turkcesiydijiv1pdf.pdf?0, [Erişim 5 Haziran 2019].

Shastri B.A., Raghav Y.S., Sahadev R., Yadav B.P., (2018), Analysis of Fire Protection Facilities in Hospital Buildings, Advances in Fire and Process Safety, (Siddiqui N.A., Tauseef S.M., Abbasi S.A., Rangwala A.S., Ed.), Springer, ss.183-190.

Şimşek Z., Akıncıtürk N, (2016), Sağllk yapılarının yangından korunma yönetmelik hükümlerinin eksik yönleri ve öneriler, Uludağ Üniversitesi Mühendislik Fakültesi Dergisi, 21(2), 283-298.

Şimşek Z., (2013), Sağlık yapılarında yangın güvenliğinin duman kontrolü sağlamasına ilişkin modelleme yöntemi, Doktora Tezi, Uludağ Üniversitesi, Fen Bilimleri Enstitüsü, Mimarlık Anabilim Dalı, Bursa. 